\title{
Tabaco y cambio social: la construcción del tabaquismo como conducta desviada
}

\author{
SusAna Rodríguez Díaz \\ Universidad Nacional de Educación a Distancia \\ srodriguez@madrid.uned.es
}

Recibido: 07.05.2010

Aceptado: 13.12 .2010

\section{INTRODUCCIÓN}

Desde su introducción en Europa procedente de tierras americanas, el tabaco ha ido experimentando importantes cambios en su valoración simbólica en función de diferentes contextos sociales y políticos, sirviendo incluso como vehículo de expresión de enfrentamientos y discordias, si bien su uso más significativo ha sido, probablemente, el de facilitar el establecimiento de vínculos sociales mediante su regalo, su intercambio y su ingestión en grupo. Su forma de consumo es un lenguaje que ha definido posiciones sociales y maneras de ser en base a gran variedad de significados mitificados por los anuncios publicitarios y el cine. El formato de consumir tabaco más conocido en la actualidad, el moderno y funcional cigarrillo ${ }^{1}$, se populariza a finales del siglo XIX gracias a la publicidad y al surgimiento del paquete de cigarrillos, que permite la visibilidad de las marcas. La mecanización permitió una producción rápida y masiva de un producto que se convirtió en emblema de la modernidad, algo especialmente acentuado en España, donde la publicidad de tabaco se vale del reclamo a lo americano y al universo de la modernidad (Madrid, 2007).

Sin embargo, en las últimas décadas hemos asistido a una proliferación de acciones y discursos institucionales en relación al tabaco que tienen como objetivo la modificación tanto de la valoración social como de la práctica de consumir esta sustancia. Esto abarca tanto la creciente regulación y normalización del

${ }^{1}$ A pesar de que existen otros formatos de consumir tabaco, en el presente estudio nos hemos centrado en el cigarrillo, por ser la forma más popular de consumo en la actualidad. Empero, sí interesa señalar que formatos de consumo como la pipa o el cigarro no han sido tan fuertemente estigmatizados al consumirse de un modo más pausado y minoritario. El cigarro -símbolo de conservadurismo, poder y masculinidad-incluso ha experimentado un gran auge desde los años noventa del siglo XX, como puede observarse en publicaciones como Cigar Aficionado.

EMPIRIA. Revista de Metodología de Ciencias Sociales. N. . 21, enero-junio, 2011, pp. 121-142. ISSN: $1139-5737$ 
tabaco como la construcción de un nuevo sistema ideológico, transmitido a través de campañas diseñadas para caracterizar al tabaco como enemigo social.

Tal y como planteamos en trabajos anteriores (Rodríguez Díaz, 2005, 2006 y 2007), dentro de este fenómeno conocido como «cruzada antitabaco» llama la atención la utilización de un doble repertorio léxico: un vocabulario de tipo bélico y otro de carácter religioso. Aplicando un análisis socio-metafórico del lenguaje, según el cual las metáforas elegidas por una colectividad para nombrar una parcela de la realidad reflejan e instituyen presupuestos ideológicos y culturales (Lizcano, 1999), apuntamos la idea de que la vertiente religiosa de este tipo de retórica podría indicar que la secularización de las sociedades industrializadas no ha supuesto declive, sino mutación, de funciones religiosas. El aspecto bélico nos remite a un proyecto de modernización que, en el caso del tabaco, se encuentra inacabado, y que implica la consecución de un orden mediante la aplicación de la represión por parte del Estado, que es, en las sociedades modernas, el que ostenta el monopolio del empleo de la fuerza para instaurar y mantener el orden social.

Ambos aspectos de este fenómeno nos serán útiles en el análisis que, a continuación, presentamos, en torno las estrategias que se han utilizado para convertir al hábito de fumar en conducta desviada, que ilustraremos con ejemplos tomados de los medios de comunicación ${ }^{2}$ y de fuentes institucionales.

En el proceso de construcción del tabaquismo como conducta desviada, distinguiremos una patologización en términos médicos, que convierte al tabaco en enemigo a combatir. El fumador es un enfermo -en virtud de su condición de adicto- o una persona propensa a contraer enfermedades -en virtud de la nocividad del tabaco para la salud- y a provocar que otros -fumadores pasivos- las contraigan. Este último argumento ha sido esencial para justificar que el fumador haya sido segregado, esto es, que haya visto reducido el ámbito en el que puede ejercer su condición de consumidor de tabaco, tendencia progresiva que va en la dirección de abarcar todos los espacios públicos cerrados e, incluso, algunos al aire libre. La separación entre espacios libres de humo y espacios contaminados por el humo del tabaco nos remite, a su vez, a una estigmatización del hábito de fumar, que implica la consideración de que el tabaco constituye una amenaza para la pureza del cuerpo individual y social, así como a su utilización como chivo expiatorio. Además, se aplican al fumador medidas -y discursos- de tipo bélico, lo que conlleva su criminalización, al haberse convertido el tabaquismo en

2 Autores como Sánchez Noriega (2002) destacan el papel de los medios de comunicación como elemento de socialización permanente al proporcionar actitudes, interpretaciones y conclusiones previamente organizadas. Al ser prácticamente el único canal de comunicación entre el sistema político y la ciudadanía son, a menudo, instrumentos eficaces para la conservación -o cambiodel orden establecido a través de la repetición -o alteración- de ciertas opiniones y actitudes. A todo esto hay que añadir la circunstancia de que los medios de comunicación masivos se mueven, de manera creciente, por objetivos de tipo mercantilista, por lo que se tiende a buscar la espectacularidad, distorsionando la información para hacerla más atractiva y poniendo más énfasis en lo conflictivo, polémico, sensacionalista y dramático.

EMPIRIA. Revista de Metodología de Ciencias Sociales. N. ${ }^{\circ}$ 21, enero-junio, 2011, pp. 121-142. ISSN: 1139-5737 
un terrible enemigo que hay que exterminar. Por último, el fumador es considerado como un desviado en términos sociales, lo que supone la inversión valorativa de la costumbre de fumar, que se va convirtiendo en algo minoritario, molesto, anormal y mal considerado ${ }^{3}$.

\section{EL TABAQUISMO COMO PATOLOGÍA}

Mucho han cambiado las cosas para el tabaco desde que Monardes ${ }^{4} \mathrm{y}$ otros médicos alabaran sus virtudes o, más recientemente, desde que, en los años cincuenta del siglo XX, científicos y profesionales de la medicina recomendaran determinadas marcas de cigarrillos 5 . Lo que ya en el siglo XVI empezaba a ser patente era el surgimiento de la autoridad del saber científico en detrimento de otras fuentes de conocimiento, como la religiosa y la popular, hasta el punto de que, con el avance del proceso modernizador, se acabaría convirtiendo en única e incuestionable.

La medicalización del tabaquismo, esto es, la caracterización del hábito de fumar como objeto del saber médico ha sido un paso esencial en el proceso de desprestigio del tabaco. Como señala Susan Sontag (2005), la enfermedad es metáfora de desórdenes en la vida social, lo que podría contribuir a explicar la relevancia simbólica que tienen las «campañas» destinadas a «combatir» el uso

${ }^{3}$ En la investigación que realizamos acerca del tabaco, que sirvió de base para la elaboración de nuestra tesis doctoral, se hizo hincapié en la dimensión histórica, realizando un análisis de los cambios que iba experimentando la valoración social del consumo de tabaco en la cultura occidental a medida que avanza el proceso de modernización, así como en las tendencias sociales que se oponen a la actual cruzada en contra del consumo de esta sustancia. Para ello, se empleó abundante material documental, procedente de fuentes históricas, literarias, científicas, gubernamentales, fílmicas, publicitarias y «populares». En el presente texto, sin embargo, tan sólo nos hemos centrado en la elaboración de un esquema de análisis de las principales dimensiones que se pueden distinguir en la reciente construcción social del tabaquismo como conducta desviada, proporcionando ejemplos significativos al respecto.

${ }^{4}$ Nicolás Monardes fue uno de los principales impulsores de la fama de las propiedades curativas del tabaco. Su trabajo más significativo y conocido fue La Historia Medicinal de las cosas que se traen de nuestras Indias Occidentales, cuya segunda parte, publicada en 1571, contiene referencias a las virtudes del tabaco. El reconocimiento de las virtudes del tabaco no impedía, en aquel momento histórico, que se incidiera en los peligros de su uso inmoderado. No es, pues, tan novedosa como suele pensarse la idea de que el tabaco pueda perjudicar la salud. Lo que sí es novedoso es que no se reconozca la posibilidad de un consumo moderado y mínimamente dañino, y que no se difundan sus virtudes terapéuticas.

5 En pleno apogeo del poderío de la industria tabacalera moderna y su omnipresencia en el cine y la publicidad emitida en televisión, varias marcas de cigarrillos utilizaron a la clase médica para promocionar sus productos. Es el caso de Camel, que en los años cincuenta realizaba anuncios publicitarios con eslóganes como «More doctors smoke Camel than any other cigarrette» («Los médicos prefieren fumar Camel a otras marcas de cigarrillos»). Otro fabricante, Chesterfield, presentaba informes avalados por médicos en los que, durante seis meses, se había hecho un seguimiento de fumadores de esta marca y se había comprobado que no dañaban oídos, nariz, garganta ni otras partes del cuerpo. «Recuerde este anuncio y compre Chesterfield».

EMPIRIA. Revista de Metodología de Ciencias Sociales. N. ${ }^{\circ}$ 21, enero-junio, 2011, pp. 121-142. ISSN: $1139-5737$ 
de sustancias como el tabaco. Emplear una imaginería militar en actuaciones de tipo sanitario justifica la violencia de Estado y la consideración de que hay partes del cuerpo político que deben ser exterminadas.

Destacar los aspectos negativos del consumo de tabaco ha sido un paso imprescindible para legitimar su regulación y la aplicación de medidas «duras» a la hora de erradicar este hábito, como da fe la utilización de metáforas bélicas para describir las «estrategias» aplicadas por diversas instituciones, lo que implica la construcción de un enemigo ante el que hay que actuar con todos los medios posibles. A continuación, reproducimos uno de los muchos ejemplos de la retórica bélica utilizada en los discursos mediáticos en relación al tabaco:

La guerra ${ }^{6}$ contra el tabaquismo es un combate hasta la muerte [...] lo que hace falta es una estrategia acompasada de objetivos viables y una acción contundente y sostenida (El Mundo, 31/V/2001).

La progresiva extensión de la medicalización no sólo se pone de manifiesto en que lo que antes era un hábito se haya convertido en objeto de saber médico. Diversos aspectos de la existencia, como el atractivo sexual o la estética, han pasado a ser campo del saber científico, lo que tiene su reflejo en el mundo del tabaco. Así, se afirma que «fumar provoca impotencia» y que «fumar provoca el envejecimiento de la piel». Una llamativa campaña dirigida a los jóvenes, ideada por el Servicio Nacional de Salud del Reino Unido (NHS), utilizaba imágenes como una analogía de la impotencia representada mediante dos dedos de un hombre -metáfora de las piernas- sosteniendo un cigarrillo -el pene- que se iba consumiendo gradualmente, así como frases bastante coloquiales, como: «¿Fumar te hace duro? No si eso significa que no puedes levantarla». Los mensajes dirigidos a las mujeres se basaban en la disminución del atractivo físico. Así, la televisión ofrecía un anuncio en el que se veía cómo un joven dejaba de acercarse a una fumadora al percibir su mal olor. «Si fumas, apestas», rezaba uno de los eslóganes. En prensa, se jugó con imágenes de antes y de después. Así, se mostraba cómo una fumadora perdía su belleza cuando le salíaen arrugas alrededor de los labios o al mancharse sus dientes. Además, se creó una revista titulada Ugly (Feo/a), con un formato similar al de las publicaciones dirigidas a los adolescentes, en la que se resumían los efectos del tabaco y se daban consejos para dejar de fumar.

Como puede observarse en estos ejemplos, la medicina no se preocupa solamente de las técnicas de la curación, sino también de proporcionar una definición del hombre modelo. Al adoptar una postura normativa, no sólo da consejos de vida saludable, sino que se considera con derecho a regir las relaciones físicas y morales del individuo y de la sociedad. Esto significa tanto la bipolaridad entre lo normal y lo patológico como la convergencia entre ideología política e ideología médica. Como argumenta Michel Foucault, la normalización de los ciudadanos ha sido esencial para el funcionamiento de las sociedades capitalis-

${ }^{6}$ Las cursivas se utilizarán para destacar términos significativos.

EMPIRIA. Revista de Metodología de Ciencias Sociales. N. ${ }^{\circ}$ 21, enero-junio, 2011, pp. 121-142. ISSN: 1139-5737 
tas, así como la disciplinarización y el control de los desviados. Dado que existen grupos sociales que tienen capacidad para imponer sus normas a otros grupos sociales, la cuestión de la desviación de las normas es un problema de poder. Bajo esta luz es más fácil comprender titulares como el que sigue: «El Gobierno fomentará con una ley los hábitos sanos» (El País.com, 10/III/2009):

«Los españoles tenemos que aprender a cuidar nuestra salud y esforzarnos para adquirir nuevos hábitos de vida y practicarlos», explica Josefa Ruiz, secretaria de Salud Pública de Andalucía. Como ha quedado claro en el congreso de SESPAS, ahora toca, entre otras cosas, cuidar la dieta, hacer ejercicio físico, evitar el tabaco y el consumo excesivo de alcohol.

A continuación desarrollamos los pilares en los que se sustentan las argumentaciones en contra del tabaco: la nocividad del tabaco para la salud -que permitirá convertir al tabaco en enemigo social y despojar al acto de fumar de sus connotaciones positivas-, la caracterización del tabaquismo como enfermedad -concepto clave para justificar la intervención médica en el ámbito de las conductas, además de cuestionar la libertad del que fuma, que es catalogado de adicto- y la creación del concepto de fumador pasivo -que permite justificar la prohibición de fumar en espacios públicos.

\section{La dicotomía: tabaco o salud}

Desde la década de los años ochenta es fácil encontrar, en los medios de comunicación, discursos en los que se contrapone el tabaco al valor salud. Por ejemplo, en 1980, la Organización Mundial de la Salud ${ }^{7}$ lanzaba el mensaje de que esta sustancia es enemiga de la salud, al elegir como lema para conmemorar el Día Mundial de la Salud: «Tabaco o salud, elija».

Poco después, en 1983, en Gran Bretaña, el Colegio de Médicos lanzaba un informe titulado Tabaco y salud, en el que se afirmaba que el tabaco es «comparable a las devastadoras epidemias infecciosas del pasado». El documento atacaba a los políticos y a las autoridades por ser casi insensibles a este grave problema y por no evitar el holocausto que supone el consumo de cigarrillos. Al caracterizar así al tabaco parece lógico que se pida la prohibición de la promoción de venta de tabaco, que finalice el patrocinio por firmas tabaqueras de acontecimientos deportivos, que se aumenten los impuestos sobre los cigarrillos y que se reduzcan los niveles de nicotina, alquitrán y monóxido de carbono permitidos. El lenguaje alarmista y de urgencia al que nos venimos refiriendo se completa con la publicación, en 1985, de un informe que lleva por título La gran masacre, editado por el Health Education Council conjuntamente con la Asociación Médica de Gran Bretaña, en torno a las muertes ocasionadas por el tabaco.

\footnotetext{
${ }^{7}$ En adelante, OMS.
}

EMPIRIA. Revista de Metodología de Ciencias Sociales. N. 21, enero-junio, 2011, pp. 121-142. ISSN: $1139-5737$ 
Titulares tan espectaculares como «El tabaco y el alcohol, principales verdugos» (El País, 21/II/1986), son los que permitirán justificar que se nombren -y conciban- en términos bélicos las acciones institucionales emprendidas en relación al hábito de fumar. Así, a finales de la década, con motivo del lanzamiento de un programa llamado «Europa contra el cáncer», se afirma que «el enemigo público número uno es el tabaco». Por su parte, la OMS editaba un folleto cuyo título es suficientemente explícito: «Tabaco o salud, elija la salud», que contenía preguntas y respuestas destinadas a disipar toda duda sobre la nocividad del tabaco (El País, 7/V/1988).

La propaganda antitabaco, únicamente centrada en los efectos dañinos del tabaco para la salud, no deja apenas lugar para discursos que hagan referencia a la posible ambivalencia de esta sustancia, que puede ser beneficiosa para unas cosas aunque sea perjudicial en otros sentidos, dependiendo, además, de la cantidad que se consuma, del tiempo que se lleve consumiendo e, incluso, de su forma de administración. Los discursos en torno al tabaco son mucho más simplistas y genéricos. Por ejemplo, en El periódico de la Farmacia ( $2^{\mathrm{a}}$ quincena de enero de 2009), de distribución gratuita en farmacias, podía leerse en portada el siguiente titular: «La cantidad no importa, el tabaco mata igual. Fumar menos de cinco cigarrillos al día triplica el riesgo de morir por un infarto o un cáncer de pulmón».

En los últimos años, la relación entre tabaco y enfermedad se ha convertido en amplio campo de estudio para los científicos, con gran presencia de artículos en torno al tema en revistas especializadas, cuya publicación se suele reflejar en los medios de comunicación. Al tabaco se lo vincula con todo tipo de enfermedades, lo que acaba por hacer de esta sustancia el producto más dañino de todos los que se pueden consumir.

En ocasiones, la consideración de que el fumador es más susceptible de enfermar ha estado acompañada de claros actos discriminatorios. Así, a algunos fumadores se les ha llegado a negar asistencia médica, como le sucedió a Harry Elphick, que murió después de que los médicos de un hospital de Manchester se negaran a efectuarle un chequeo por ser fumador. Tras este caso, se descubrió la discriminación sanitaria que existía hacia obesos, ancianos y bebedores, junto con los fumadores. En otros países, como Alemania, el Gobierno llegó a proponer un incremento de la Seguridad Social a los fumadores, utilizando el razonamiento de que este colectivo estaba poniendo en peligro su salud. En varios países, algunas compañías ofrecen seguros más baratos para los que no fuman, alegando que los fumadores arriesgan más su salud.

Un titular enormemente explícito es el aparecido en la edición digital de $E l$ País (11/V/2007): «Ni gordos, ni gays, ni fumadores. La Organización Internacional del Trabajo alerta sobre las nuevas formas de discriminación»:

El estilo de vida de la persona y, más concretamente, el estilo de vida sano, se está convirtiendo, según la OIT, en otro factor determinante para la obtención o la pérdida de un puesto de trabajo. Tener sobrepreso, fumar o sufrir hipertensión puede ser una desventaja en algunos países industrializados.

EMPIRIA. Revista de Metodología de Ciencias Sociales. N. ํ 21, enero-junio, 2011, pp. 121-142. ISSN: 1139-5737 


\section{Fumar como adicción}

Como ya se apuntó, la medicalización del tabaquismo ha llevado a la caracterización de este hábito como objeto de saber médico. En este proceso, ha sido esencial el concepto de adicción. A partir de los años sesenta del siglo XX, diferentes instituciones comenzaron a señalar la capacidad adictiva de la nicotina aunque, en 1964, fumar todavía era clasificado como hábito en las definiciones que, sobre hábito y adicción, realizó la OMS. Es en 1969 cuando cambiaba el término hábito por el de dependencia al que, en 1981, se agregaban los conceptos de dependencia física y psíquica.

La asociación con el mundo de las drogas sería uno de los primeros pasos para esta conceptualización. Caracterizar al fumador como drogadicto y, por tanto, como enfermo, ha sido fundamental para invertir el valor simbólico del tabaco y que éste pasase a arrastrar todas las connotaciones negativas asociadas con el término «droga», como la idea de su maldad absoluta y su asociación con sectores marginales de la sociedad.

La vinculación del tabaco con la parte más áspera y estigmatizada del mundo de las drogas, la tan temida heroína, recibió un contundente respaldo gracias al Surgeon Report de 1988, en el que se equiparaba a los fumadores con los heroinómanos. Esta asociación se ha mantenido hasta la actualidad. Por ejemplo, Carlos Jiménez Ruiz, Presidente de la Sociedad Madrileña de Neumología y Director de la Unidad de Tabaquismo del Hospital de la Princesa, se expresaba en estos términos:

Según las investigaciones, la nicotina tiene tanta capacidad adictiva o más que la heroína. Cuesta más dejar la nicotina que la heroína (Tiempo, 1/XI/1999).

Ante las drogas, pues, sólo cabe una actitud: el rechazo. Así, si se caracteriza la nicotina como droga y al fumador como adicto, se pueden trasladar al mundo del tabaco estereotipos construidos en torno a las drogas, como el tan temido síndrome de abstinencia. En la página web del NIDA (National Institute on Drug Abuse), dependiente del gobierno de Estados Unidos, se puede encontrar una muestra del típico discurso en torno al tabaco como droga y los efectos de su privación:

Las personas adictas a la nicotina presentan los síntomas del síndrome de abstinencia cuando tratan de dejar de fumar. Por ejemplo, un estudio encontró que cuando fumadores crónicos se privan de fumar cigarrillos durante 24 horas presentan irritabilidad, hostilidad, agresión y disminución de la actitud de cooperación social [...]. Durante los períodos de abstinencia o cuando tienen ansias excesivas de fumar, se ha demostrado que los fumadores sufren un deterioro en una amplia gama de funciones sicomotoras o cognitivas tales como la comprensión del lenguaje. 
No cabe duda, entonces, de que, por su condición de enfermo, el fumador debe ponerse en manos de un experto que le ayudará a interiorizar una determinada visión de sí mismo para, después, seguir un tratamiento determinado. Desde esta perspectiva, se afirma que el fumador es dependiente de la nicotina; que la nicotina le proporciona una homeostasis de su neuroquímica cerebral y al consumir nicotina evita sentirse mal; que durante los años de fumador ha asociado el consumo de tabaco a una multitud de situaciones cotidianas y que cuando se enfrente a ellas se pondrán en marcha mecanismos que le llevarán sin «una conciencia clara» a buscar la nicotina (estímulo ambiental condicionado); y que el éxito de su tratamiento depende de que no vuelva a usar tabaco:

[La intervención especializada se orienta hacia] la toma de conciencia por parte del enfermo de su problemática y consecuencias, haciéndole ver la necesidad de ayuda y de su implicación en un proceso terapéutico amplio. El profesional debe informar al dependiente $\mathrm{y}$, cuando ello sea apropiado a otras personas relevantes, respecto a la etiología y curso del trastorno, la necesidad de evitar la sustancia, el riesgo de un cambio de adicción, la identificación de los factores que desencadenan las recaídas, los tratamientos existentes y el papel de la familia y los amigos en cuanto a facilitar o impedir la recuperación (Marcos, 1999:121).

Las descripciones en torno a la abstinencia del tabaco se redactan en términos técnicos y generales, sin tener en cuenta la existencia de casos y personas individuales. Discursos así borran cualquier referencia al entorno cultural y social de cada individuo, a su manera de sentir particular; entramos en el dominio de un determinismo que despoja de libertad y de sentido a las acciones humanas.

Sin embargo, en ocasiones sí interesa destacar que el tabaquismo es un enfermedad «social»:

Los fumadores deben tratarse en la sanidad como se trata, por ejemplo, a un paciente que tiene el colesterol alto. El fumador, sin embargo, no debe ser culpabilizado, ya que es un producto de la sociedad (El País, 30/V/2001).

Esta significativa declaración, realizada por Vera Luiza da Costa, responsable de la OMS contra el tabaco, evidencia hasta qué punto el consumo de esta sustancia se ha medicalizado. Las adicciones han pasado a ser consideradas como enfermedades cuyo origen está en el medio social. La medicina no es, por tanto, ajena a cuestiones sociales, pues debe intervenir para corregir conductas y comportamientos.

En íntima relación con la consideración del tabaquismo como enfermedad de la sociedad es la analogía que se establece entre la adicción y una enfermedad infecciosa, que permite explicar la propagación de una conducta en términos médicos (contagio) y justificar por qué no todos los individuos se comportan de la misma manera: 
Las adicciones a las drogas son en muchos aspectos como enfermedades infecciosas: un virus o una bacteria infecta algunas personas pero no a todos; hay grados diferentes de inmunidad relativa [...]. Las personas portadoras de un agente infeccioso pueden transmitir la enfermedad a otras personas susceptibles no contagiadas todavía. Una enfermedad infecciosa es contagiada con más facilitad por personas que la han contraído recientemente (Goldstein, 1995:22).

Alusiones al tabaquismo como «pandemia», esto es como enfermedad contagiosa en el llamado Tercer Mundo, acompañadas de cifras catastróficas de costes humanos y económicos hacen del tabaco un terrible enemigo que pone en riesgo millones de vidas y amenaza con hundir economías enteras.

\section{El concepto de «fumador pasivo»}

Una idea que prestó -y continúa haciéndolo- gran rentabilidad al movimiento antitabaco -pues justifica el establecimiento de regulaciones más severas en torno a este producto, desplazando el problema del consumo del tabaco fuera de los límites del ejercicio de la libertad individual, valor tan defendido por las democracias occidentales- es que los cigarrillos no sólo son nocivos para el que fuma, sino también para el que no fuma, que acaba desembocando en la creación del concepto de «fumador pasivo», esto es, de alguien que fuma involuntariamente, con toda la carga emotiva que ello conlleva (son víctimas del humo que los fumadores les obligan a ingerir en contra de su voluntad). La creación de esta figura supone un salto conceptual desde a la idea ancestral de que consumir esta sustancia en presencia de otros les puede causar molestias a la noción de que consumir tabaco en presencia de otros perjudica su salud.

En 1980, científicos de la Universidad de San Diego (California) habían afirmado que los bronquios y las cavidades alveolares de los no fumadores podían verse afectadas por el humo. Sin embargo, el documento más influyente en relación a este tema fue el publicado en 1981 por el British Medical Journal. Dirigido por el doctor Takeshi Hirayama, este estudio analizaba la mayor incidencia del cáncer de pulmón entre mujeres no fumadoras que tenían maridos fumadores. A pesar de que se señalaron algunas deficiencias en su metodología ${ }^{8}$, se convertiría en un artículo muy citado a la hora de demostrar los daños para la salud de las personas que se encuentran cerca de alguien que fuma.

En 1984, el director general de Salud de Estados Unidos, Everett Koop, hacía público el informe correspondiente a ese año sobre el tabaco, en el que se afirmaba que existía una relación entre el consumo de cigarrillos por parte de los padres y el aumento de enfermedades respiratorias en los hijos. En los años noventa salí-

${ }^{8}$ Hirayama se había servido de un test inventado por Mantel que, al conocer el estudio, realizó un análisis del mismo, señalando varias ambigüedades y omisiones, afirmando que su autor había cometido graves errores estadísticos (véase Hatton, 2000).

EMPIRIA. Revista de Metodología de Ciencias Sociales. N. ${ }^{\circ}$ 21, enero-junio, 2011, pp. 121-142. ISSN: $1139-5737$ 
an a la luz pública estudios como el que presentaba la Agencia para la Protección del Medio Ambiente (EPA) y la Secretaría de Salud y Recursos Humanos del Gobierno estadounidense, que afirmaba que los fumadores pasivos, especialmente los niños, corrían el riesgo de morir de cáncer o padecer asma, bronquitis y neumonía. Por su parte, el Scientific Comité on Tobacco and Health (Comité Científico sobre Tabaco y Salud, SCOTH) del Gobierno británico consideraba en su informe de 1999 que «el humo inhalado involuntariamente provocaba cáncer de pulmón y era la causa de enfermedades respiratorias infantiles». También parecía estar demostrado que el tabaquismo pasivo está en el origen de enfermedades cardiacas isquémicas y de la muerte súbita del lactante (Gately, 2003:333-334).

Hoy día, el tabaquismo pasivo está incorporado a las preocupaciones en relación al tabaco, siendo una razón para demandar la creación de lugares específicos para fumadores en espacios de convivencia e, incluso, para la total prohibición del consumo de tabaco en lugares públicos, así como para concienciar a los padres de la necesidad de no fumar en presencia de sus hijos o de abandonar su hábito. Así, por ejemplo, con motivo de la campaña de la Comisión Europea «Help, por una vida sin tabaco», se afirmaba:

Un estudio publicado en abril de 2004 por el British Medical Journal [...] hace hincapié en los terribles efectos del tabaquismo pasivo. Según los autores, el riesgo de mortalidad es un $15 \%$ más alto entre los adultos que conviven con un fumador aunque no hayan fumado nunca [...]. Además, el humo del tabaco afecta especialmente a los niños, aumentando el riesgo de sufrir infecciones respiratorias, infecciones auditivas recurrentes, ataques de asma, retraso en el desarrollo intrauterino, bajo peso al nacer y muerte súbita del lactante.

En los últimos años, gran cantidad de estudios reflejan la variedad de daños del tabaco para la salud de los que rodean al que fuman. Titulares de prensa como «El tabaco mata a 3.000 no fumadores cada año» (El Pais.com, 9/I/2008), insisten en las evidencias existentes acerca de la nocividad del humo del tabaco y en la victimización de los fumadores pasivos. Así, según un estudio realizado en España y publicado en Tobacco Control:

El último cálculo presentado cifra en 1.228 las personas víctimas del vicio de los demás sólo en el trabajo. La cifra pasa de las 3.000 personas (3.237) si se incluyen quienes están sometidos a los malos humos de los demás también en los locales de ocio.

En 2006, el Ministerio de Sanidad y Consumo lanzaba en España una campaña que hacía hincapié en los riesgos que, para los niños, supone la ingestión del humo procedente de la combustión del cigarrillo, que ahora se conoce con el término técnico ACHT (aire contaminado por el humo del tabaco). Con ligeras variantes, las cuñas de radio y los anuncios de cine y televisión exprimían al máximo el concepto de «fumador pasivo», al caracterizar a los niños expuestos al humo del tabaco de los adultos como fumadores en contra de su voluntad: 
Pablo, 4 años, fuma un paquete un medio al día

Laura, 6 años, fuma doce cigarrillos al día

Sergio aún no ha nacido y ya está empezando a fumar.

Porque cada vez que fumas un cigarrillo delante de un niño

Estás obligándole a respirar el humo del tabaco

Con graves consecuencias para su salud

Elige espacios sin humo

Por lo que más quieras

\section{EL FUMADOR SEGREGADO}

Una de las estrategias utilizadas para crear un colectivo marginado, el de los fumadores, ha sido -además de hacer hincapié en la nocividad del tabaco- visibilizarlo y aislarlo, expulsándolo de muchos de los espacios en los que se convive (espacios «sin humo»), marcando zonas específicas para cultivar su hábito, reduciendo su presencia en los medios de comunicación y en el cine, prohibiendo la publicidad del tabaco, restringiendo sus puntos de venta y marcando las cajetillas con mensajes que hacen referencia a su condición de veneno. Con todas estas medidas se consigue la menor visibilidad posible del acto de fumar en el conjunto social y, simultáneamente, la máxima visibilidad cuando el fumador ejerce su condición en público. Buenos ejemplos de la retórica de confinamiento utilizada en los medios de comunicación a la hora de caracterizar la persecución del hábito de fumar lo constituyen los siguientes titulares:

«Europa y Estados Unidos empiezan por fin a acorralar al tabaco y a los fumadores» $(A B C, 16 / \mathrm{I} / 2003)$.

«En EE.UU., una oleada de leyes y restricciones han cercado a los fumadores» (La Voz de Galicia, 31/X/2005).

Otro ejemplo lo encontramos a raíz de la entrada en vigor en España del Plan Nacional de Prevención y control del Tabaquismo, cuyos objetivos eran los siguientes:

[...] liberar de humo los espacios de convivencia públicos, incluidos los centros de trabajo, haciendo recular a los fumadores a zonas específicas donde cultivar su vicio (El País, 16/I/2003).

Con motivo de la promulgación en España de la Ley 28/2005, de 26 de diciembre, de medidas sanitarias frente al tabaquismo y reguladora de la venta, el suministro, el consumo y la publicidad de los productos del tabaco ${ }^{9}$, se habló de objetivos como el de «liquidar la cultura del tabaco», o iniciar el «destierro del tabaco al ámbito privado» (La Vanguardia, 31/XII/2005).

${ }^{9}$ En adelante, Ley 28/2005.

EMPIRIA. Revista de Metodología de Ciencias Sociales. N. ${ }^{\circ}$ 21, enero-junio, 2011, pp. 121-142. ISSN: $1139-5737$ 
En estos ejemplos se observa un vocabulario que hace hincapié en el exterminio y el apartamiento. Como resultado de este proceso se llega a hablar del surgimiento de la figura del «fumador callejero» que, como un perro, deambula a la puerta de su empresa (Efe, 2/I/2006), tras la entrada en vigor de uno de los aspectos más restrictivos de la Ley 28/2005, la prohibición de fumar en los centros de trabajo.

La creación de espacios acotados para los fumadores va asociada, a menudo, a la utilización de una terminología bélica, que se asocia con el hecho de regular. El mensaje parece ser el siguiente: la implantación de normas conlleva el uso de la fuerza, pero ello está justificado, pues se trata de garantizar nada menos que la «limpieza» del aire, su «pureza». Se hace patente así la conexión de la cruzada antitabaco con el movimiento higienista, que se encuentra en el corazón del proyecto modernizador y que lleva aparejada la necesidad de racionalizar, de normalizar, de establecer sistemas de control: Un ejemplo de esta retórica lo encontramos en el siguiente artículo aparecido en prensa: «EE UU propone que sólo se pueda fumar en zonas acotadas» (El País, 26/III/1994):

La Administración norteamericana lanzó ayer una nueva ofensiva para regular los espacios de fumadores en los lugares de trabajo y garantizar la limpieza del aire en los locales de todo el país, incluidos bares y restaurantes. [...] Las disposiciones sobre pureza del aire afectarán a 4,5 millones de restaurantes, cafeterías, hoteles, colegios y centros de salud.

Para una mejor comprensión de estos discursos puede resultar de utilidad valernos de la distinción que estableció Durkheim (1982) entre lo sagrado y lo profano como característica del fenómeno religioso. Así, podríamos considerar que ha tenido lugar una sacralización del espacio público, al crearse lugares diferenciados para fumadores y no fumadores; dentro de estos, los primeros podrían considerarse como «impuros» o contaminados, frente a los segundos, que podríamos catalogar domo «puros», esto es, limpios, sin contaminar. Además, puede ser útil recordar cómo, para Mary Douglas (1991), existe una relación entre contaminación y moral, pues la gente piensa que su medio social consiste en que las personas están juntas o separadas por líneas que deben respetarse. En este sentido, puede decirse que, en la actualidad, se está percibiendo el tabaco como sustancia contaminante que amenaza la «pureza» del cuerpo individual y social, lo que enlaza con el siguiente apartado, que dedicamos a la dimensión religiosa de la construcción social del tabaquismo como conducta desviada.

\section{TABACO Y ESTIGMA}

Según Durkheim y Freud, el control social necesita de una definición de desviación social, pues el castigo simboliza el consenso de una comunidad en rela- 
ción a los valores violados por el sancionado, contribuyendo a la creación de la solidaridad social.

Por su parte, René Girard (1986, 1995) subraya la identificación formal entre la violencia y lo sagrado en función del mecanismo de la víctima propiciatoria, que es frecuentemente destruida y expulsada de la comunidad. Es esto lo que hace posible la vida social pues, mediante esta catarsis, la sociedad se ve purificada y cohesionada. La función esencial de la guerra y de los ritos que la acompañan consiste en preservar el equilibrio y la tranquilidad, alejando la amenaza de una violencia más intestina. Como ya observamos, el tabaco, etiquetado como veneno ( «fumar puede ser causa de una muerte lenta y dolorosa») se ha unido a la categoría de sustancias conocidas con el nombre de «drogas», que comenzaron a ser estigmatizadas a principios del siglo XX.

Siguiendo con Girard, para que un ser se convierta en susceptible de ser víctima propiciatoria, es necesario que esté fuera de la comunidad, bien porque nunca ha pertenecido a ella, bien porque se le aparta de ella. Cuando el sacrificado es elegido dentro de la comunidad, pasa a ser un ser diferente del resto. La víctima propiciatoria alcanza un carácter monstruoso, dejándose de ver en ella lo que se ve en los restantes miembros de la comunidad. A menudo se eligen seres de categorías no abiertamente exteriores, sino más bien marginales, pues para que las tendencias agresivas se puedan transferir es preciso que la víctima no sea ni demasiado extraña ni demasiado poco extraña, ambigüedad necesaria para la eficacia catártica.

El sacrificado debe encarnar un monstruo, por lo que hay que eliminar su exceso de humanidad. Puede explicarse así el que se recurra con frecuencia a la animalización para referirse al fumador. Así, por ejemplo, Allen Carr (2003), gurú del abandono del tabaquismo, considera que la adicción a la nicotina es un «monstruo». Recordemos la figura del «fumador callejero», la campaña británica «Ugly» y veamos más ejemplos de este mecanismo, como otra campaña lanzada en el Reino Unido en los años ochenta en la televisión y en historietas impresas -distribuidas en las escuelas y centros juveniles- para combatir la tentación de fumar entre los adolescentes, que recurría a la dramatización de la lucha del bien contra el mal, encarnados en Superman y el malvado Nick O'Tean (cacofonía de nicotina). Nick O'Tean, caracterizado de forma siniestra, ofrecía cigarrillos a los niños «para que así crezcan mucho y sean más fuertes», pero inmediatamente llegaba el héroe, con su capa voladora, y advertía a los niños de que su poder especial puede ver los pulmones dañados de quienes hacen caso del malvado Nick O'Tean. Finalmente, luchaban y Superman vencía. Tras la victoria, sentenciaba: «Yo nunca digo que sí cuando me ofrecen un cigarrillo».

Otro ejemplo significativo lo constituye la campaña lanzada, en el año 2006, por el Ministerio de Sanidad español, bajo el título «Gracias por no fumar», que invitaba a abandonar el tabaco basándose en el rechazo hacia el mal aliento del fumador, sus pulmones negros, su vida más corta y el perjuicio para los que le rodean. La propaganda que aparecía en televisión, cine y radio reproducía la voz de una máquina expendedora que, en vez de pronunciar la frase «Su tabaco, gracias», decía así:

EMPIRIA. Revista de Metodología de Ciencias Sociales. N. . 21, enero-junio, 2011, pp. 121-142. ISSN: $1139-5737$ 
Su aliento más pestilente, gracias

Sus pulmones más negros, gracias

Sus veinte días menos de vida, gracias

Los no fumadores más perjudicados, gracias

La salud de los que le rodean más afectada, gracias

Gracias por no fumar

Ministerio de Sanidad y Consumo

Vemos así cómo la víctima propiciatoria alcanza un carácter repulsivo, rechazable y asqueroso, perdiéndose algunos de los referentes que lo integrarían en la comunidad, como ocurre, en nuestros tiempos, con el hecho de guardar unas normas higiénicas. En relación al tabaco, lo curioso es observar cómo, progresivamente, tiene lugar un enorme cambio social. Antes, fumar era visto como algo estéticamente agradable; como vemos, en la actualidad, se tiende identificar este hábito con la suciedad. De hecho, el propio concepto de «fumador impenitente» nos remite a un ser sin posibilidad de salvación.

La creación de colectivos desviados y la guerra contra éstos sirve tanto para reforzar el consenso moral de la comunidad -creando solidaridad social acerca de los valores que se violan- como para satisfacer la fascinación que la ruptura del orden moral despierta. De hecho, el término latino sacer significa a la vez lo excelso, sagrado, sublime, eminente y venerable, así como lo reprobable, lo horroroso, lo siniestro, lo execrable (Trías, 2006:129-131).

Como comenta Richard Klein (1994), el poder de seducción del tabaco tiene que ver con el sentimiento de lo sublime: una satisfacción estética que incluye una sensación negativa, un vislumbre de mortalidad. De ahí que las campañas dirigidas a persuadir del consumo de tabaco no hayan tenido demasiado impacto en colectivos como los adolescentes, que no sólo no se preocupan en exceso por la salud -pues les sobra-, sino que se sienten atraídos por lo peligroso y prohibido. Nos referimos, por ejemplo, a la encuesta realizada a médicos de la Sociedad Española de Medicina de Familia y Comunitaria, que afirman que los mensajes de advertencia sobre los daños del tabaco impresos en los envases de tabaco (popularmente conocidos como «esquelas») no han tenido el efecto que se perseguía entre los ciudadanos de menor edad. Se dice, incluso, que las campañas agresivas pueden incitar al consumo en este colectivo, pues les puede incitar a vulnerar la norma (El País, 26/V/2004). Es más: según el Grupo Español de Cáncer de Pulmón (GECP) el consumo de tabaco entre adolescentes españoles ha experimentado un crecimiento del $40 \%$ en tan sólo 15 años (Jano On-line, 11/V/2009).

\section{EL FUMADOR COMO CRIMINAL}

En el caso del tabaco, como se ha ido argumentando, la retórica bélica es explícita desde el momento en el que el tabaco es un enemigo a combatir, una ame-

EMPIRIA. Revista de Metodología de Ciencias Sociales. N. o 21, enero-junio, 2011, pp. 121-142. ISSN: $1139-5737$ 
naza para el orden social. A la hora de referirse a este producto, se emplean con frecuencia metáforas con fuertes connotaciones criminalizadoras, como «enemigo público». «masacre», «holocausto»o «verdugo». De ahí que las campañas, las estrategias, la regulación, la vigilancia para que se cumplan las normas y las sanciones hayan ido escenificando una auténtica guerra contra el tabaco, mediante la utilización de expresiones como «batalla legal», «liquidar», «guerra sin cuartel»o «erradicación».

En un artículo aparecido en prensa (El Diario Vasco, 31/V/2003), se recogían opiniones en torno al tabaco en las que se hacía hincapié en el creciente acorralamiento del fumador:

\begin{abstract}
Ahora que te vean con un cigarro es un signo de marginado. Somos los malos. No es lógica la persecución que hay hacia nosotros.
\end{abstract}

A finales de la década de los noventa se llegó, en Estados Unidos, al extremo de convertir el fumar en una acción que podía ser sancionada penalmente, al ponerse en marcha un Tribunal Antitabaco de Menores en el sur de Florida, juzgando a los jóvenes que hubieran cometido el delito de fumar en público o sostener en sus manos una cajetilla de cigarrillos a la vista de un policía. Las penas abarcaban multas, servicios comunitarios y un curso obligatorio sobre los peligros del tabaco (El País, 27/X/!998).

La relación entre consumo de tabaco y delincuencia aparecía en los diarios españoles al poco de promulgarse la Ley 28/2005. Los titulares de diversos diarios hablaban que en Navarra había sido detenido un hombre por fumar en una zona «expresamente prohibida». Sin embargo, la razón por la que fue detenido es que se negó a identificarse y a acompañar a los policías a comisaría.

Por la forma de dar la noticia, parecería que se puede detener a alguien por negarse a dejar de fumar en una zona prohibida -lo que puede incitar a la población a cumplir las normas por miedo al castigo--, cuando lo que estipula la ley es una multa. En cualquier caso, se transmite a la ciudadanía la idea de que se está vigilando que las leyes se cumplan. Además, al fumador se le caracteriza como un ser problemático, poco amigo de cumplir las normas, lo que subraya su condición de marginado.

\title{
6. EL TABAQUISMO COMO CONDUCTA DESVIADA
}

La distinción entre lo normal y lo patológico tiene su origen en definiciones de orden moral y en la naturalización de la normalidad. En la medida en que la salud se considera como un bien que depende del comportamiento de las personas, se han ido estableciendo cosas que se deben hacer y cosas que la ponen en riesgo; esto es, se ha ido separando aquello que es normal, tanto en su sentido de conformidad con una regla establecida como en el de ser un hábito mayorita-

EMPIRIA. Revista de Metodología de Ciencias Sociales. N. ${ }^{\circ}$ 21, enero-junio, 2011, pp. 121-142. ISSN: $1139-5737$ 
rio-y aquello que es patológico- es decir, lo que no sigue la norma, según la distinción de Canguilhem (1970) ${ }^{10}$.

De hecho, el objetivo de las campañas antitabaco ha sido el establecimiento de la norma social de no fumar, algo que se subraya de cuando en cuando mediante la aparición de encuestas que indican que fumar no es un hábito mayoritario y que la mayoría de los que fuman desean abandonar su hábito ${ }^{11}$.

A continuación citamos varias frases de Gonzalo Robles, delegado del Gobierno, con motivo de la presentación del Plan Nacional para la Prevención del Tabaquismo (El País, 19///2003), que hacen referencia directa a la estrategia utilizada para ir eliminando el tabaco de la vida social española:

Primero se quitará el humo en la Administración pública; después, en grandes empresas, y así. A medida que se vaya implementando se debe sentir una presión social. Éste es un proceso de deslegitimación de conductas.

Otro ejemplo, éste curioso, lo constituyen las palabras de Jordi Sevilla, responsable del Ministerio de Administraciones Públicas, con motivo de la presentación, por parte de la entonces ministra de Sanidad, Elena Salgado, de la guía Se puede dejar de fumar: claves para conseguirlo (El Mundo, 28/VI/2005), que dan fe de lo mal considerada que está, a estas alturas de la historia, la costumbre de fumar:

Hay vida después del tabaco. Yo dejé de fumar y llegué a ministro.

Otro testimonio, a la hora de caracterizar a los alumnos de instituto fumadores, los caracteriza como los más rebeldes e indisciplinados y, por ende, peores estudiantes:

Son chavales que se quieren hacer notar, que van de distintos, de indisciplinados, de llamar más la atención. Forman el grupo de los rebeldillos. El $80 \%$ de ellos, además, son los que peores notas saca.

Si abstenerse de fumar es moderno y civilizado, seguir fumando es síntoma de atraso y de pertenencia a capas sociales inferiores, recuperando así la ancestral asociación del tabaco, sobre todo en su versión de humo, con las clases populares. En ocasiones se compara el dejar de fumar con otros avances de la modernidad, como la educación. Así, Mercedes Cabrera, Ministra de Educación y

${ }^{10}$ Aunque no ha sido nuestra intención, en el presente texto, abordar las estrategias de resistencia a la patologización de ciertas maneras de ser y de comportarse, tema que sí se abordó en nuestra investigación doctoral en torno al tabaco, sí queremos destacar la existencia de propuestas en entornos tan ajenos al mundo del tabaco como esa realidad social comúnmente denominada «discapacidad» mediante la creación del concepto de «diversidad funcional» (véase Rodríguez Díaz y Ferreira, 2008, 2010).

${ }^{11}$ Véase, por ejemplo, CIS (2006).

EMPIRIA. Revista de Metodología de Ciencias Sociales. N. . 21, enero-junio, 2011, pp. 121-142. ISSN: 1139-5737 
Ciencia, establecía un paralelismo entre consumo de tabaco y alfabetización ( $E l$ Pais.com, 8/XII/2007): «No saber leer es peor que fumar «, afirmaba, hablando de realizar una campaña para la lectura similar a la antitabaco.

La asociación del tabaco con los estratos sociales inferiores se explotó en los años noventa en campañas como la llevada a cabo en California en 1990, dirigida a jóvenes, mujeres e integrantes de minorías (negros, hispanos y asiáticos), que -se decía- eran los grupos sociales en los que el consumo de tabaco se mantenía estable.

La proximidad del tabaco con el mundo de las drogas ha sido otra manera eficaz de marcarlo negativamente pues, como ya se ha puesto en relieve, este tipo de sustancias arrastran gran número de connotaciones negativas. Así, por ejemplo, según un estudio de la Universidad de Gerona, «El 85\% de los jóvenes que fuman cigarrillos ha probado los porros» y el 46,3\% de los fumadores de tabaco son también fumadores ocasionales o habituales de porros (Europa Press, 8/I/2007).

El vínculo entre tabaco y pobreza ha sido señalado repetidamente. Por ejemplo, la OMS afirma que existe una tendencia a que sean los más pobres los que consuman más tabaco lo que, además, los empobrece más todavía, al impedirles colaborar en el mantenimiento de sus familias, además de suponer una carga añadida de atenciones médicas (El País, 31/V/2004).

Ante el abandono del tabaco, que se está generalizando en los países más avanzados, la industria del tabaco se dirige hacia colectivos más vulnerables y fáciles de disuadir: «Los enfermos mentales y los sin techo, nueva cartera de clientes», se decía en Elmundo.es salud (19/I/2006 ):

Algunos estudios sugieren que entre el $70 \%$ y el $99 \%$ de los adultos sin techo fuman y se estima que los enfermos mentales compran casi la mitad de los cigarrillos que se venden en EEUU.

Otra publicación resaltaba que fumar es algo marginal e, incluso, delictivo, con motivo de la inclusión de Altadis en su intranet de varios vídeos en los que el tabaco aparece como algo lleno de glamour $(A B C, 27 / \mathrm{VII} / 2007)$

Baño de moral para sus directivos es lo que ha buscado Altadis. Que cuando la última restricción legal les suma en la depresión, puedan refugiarse en su Intranet, en su pequeña red interna, en un universo paralelo en el que fumar vuelva a ser algo elegante y no delictivo.

Fumar puede ser un obstáculo a la hora de encontrar trabajo; al menos así lo creen los autores de la Guía de las empresas que ofrecen empleo, editada por la Fundación Universidad-empresa, destinada a proporcionar medios para conseguir un puesto de trabajo. Entre las recomendaciones que todo solicitante debería tener en cuenta cuando acude a una entrevista de trabajo, la guía señala el modo correcto de saludar, de sentarse, de contestar, y algo muy importante: «No fumes aunque te lo ofrezcan» (Actualidad Tabaquera, $\mathrm{n}^{\circ}$ 488, enero 1995: 39). 
En torno a los costes económicos que supone el fumador se han realizado gran cantidad de estudios. Así, por ejemplo, en Italia, a raíz de la entrada en vigor de una norma que prohíbe fumar en lugares públicos -sólo un 9,5\% de las empresas aclimató salas destinadas a los fumadores- se llega a la conclusión de que las pausas para fumar reducen la productividad laboral en un $10 \%$, por lo que se estudiaba reducir el salario de los fumadores. En Alemania también se descuentan las pausas para fumar y en el Reino Unido se exige, en algunas empresas, que los fumadores trabajen 30 minutos más al día. En España, una empresa pública, radicada en Bilbao, tras elaborar una tabla con los minutos de trabajo perdidos que supondrían que los trabajadores se ausentasen para fumar, decidió prohibir la salida para consumir un cigarro, pues los resultados indicaban que se perdía casi un mes de trabajo (20minutos.es, 11/IV/2005).

Un caso llamativo, pues supone una peligrosa reinvención orwelliana de la historia, fue borrar el cigarrillo que Jean-Paul Sartre sostenía entre sus dedos en la foto que aparecía en la portada con motivo de una exposición celebrada en la Biblioteca Nacional Francesa acerca de este filósofo (El País Semanal, 11/IV/2005).

Otro comentario que queríamos subrayar porque explica a la perfección el importante papel de los medios de comunicación para promocionar normativas, así como la justificación de la intervención del Gobierno en los hábitos de los ciudadanos, aparecía en el diario El País (8/I/2006) con motivo de la entrada en vigor de la Ley 28/2005:

A no pocos fumadores, ex fumadores y no fumadores les han podido parecer demasiado drástica las recientes medidas contra el tabaquismo, pero hay que admitir que se atienen a una obviedad de la cultura actual: casi todo lo que no es efectista carece de efecto social. Gracias a esta ecuación, la ley ha obtenido en estos días resultados espectaculares. El impacto mediático impulsa el cumplimiento de la inhibición personal [...]. Las 55.000 muertes atribuidas al tabaco anualmente en España legitiman la intervención del Gobierno sobre ese hábito privado [...]. Otro factor de legitimación de la norma es que el $70 \%$ de los 10 millones de fumadores dice en las encuestas que desearía dejarlo[...] Siendo un hábito, se trata sobre todo de estimular la voluntad individual de abandonarlo y, como objetivo intermedio, de reducir el número de cigarrillos diarios. La prohibición de fumar en el trabajo favorece ese efecto de manera no demasiado traumática, creando hábitos temporales más espaciados.

\section{CONCLUSIONES}

La progresiva mala reputación del hábito de fumar ha estado ligada, por una parte, a los resultados de investigaciones científicas que demuestran que se trata de una adicción que, además, perjudica la salud de los que fuman -tanto que puede llegar a matarles- y de los que rodean al fumador. Por otra parte, ha sido decisiva la progresiva regulación del mundo del tabaco -cuya publicidad y

EMPIRIA. Revista de Metodología de Ciencias Sociales. N. o 21, enero-junio, 2011, pp. 121-142. ISSN: 1139-5737 
consumo se ha ido restringiendo cada vez más- y las campañas en contra de su consumo, que proyectan una imagen negativa de esta sustancia y de los que la ingieren. A su vez, la creciente estigmatización del hábito de fumar ha provocado que la introducción de controles sobre el mundo del tabaco sea acogida de buen grado por parte de los ciudadanos.

La reducción del espacio del fumador nos lleva a la segregación de éste, que se ve apartado de prácticamente todos los espacios públicos cerrados. La retórica de confinamiento acompaña la creación de zonas específicas para cultivar el hábito de fumar, lo que acaba provocando que el que fuma se sienta presionado para dejar de fumar, o que se esconda para seguir fumando. Fumar, entonces, deja paulatinamente de ser un acto social, pasando a ser algo privado, íntimo, y casi prohibido.

La caracterización del fumador como contaminador, como ser sucio, que desprende mal olor, nos conduce a la importancia que, hoy día, ha adquirido la pureza corporal, en sustitución de la ancestral limpieza del alma. El tabaco, entonces, se convierte en chivo expiatorio, en enemigo interno que concentra odios y temores -desviando la atención de otros riesgos y peligros- lo que explica la tendencia a emplear una terminología que despoja de humanidad al fumador. Sin embargo, lo rechazable también despierta la atracción hacia lo prohibido y peligroso, propia del sentimiento de lo sublime, lo que explica la escasa eficacia que, entre los más jóvenes, tienen las campañas antitabaco que pueden, incluso, llegar a ser contraproducentes.

Otro mecanismo de importancia a la hora de transformar al hábito de fumar en conducta antisocial ha sido la regulación del mundo del tabaco, junto con la terminología criminalizadora y bélica que ha ido acompañando a estas medidas. Las numerosas restricciones en torno al consumo de tabaco hacen que el fumador pueda, fácilmente, convertirse en delincuente si quiebra las leyes. De hecho, al fumador se le caracteriza como un ser problemático, poco amigo de cumplir las normas, lo que subraya su condición de marginado. Además, el tabaco se ha ido construyendo, retóricamente, como enemigo de la sociedad que, en virtud de su condición de asesino debe ser erradicado.

En definitiva, el acto de fumar se va construyendo como conducta desviada de la norma social. Fumar pasa a ser considerado como un hábito minoritario, molesto y anormal, algo que las campañas antitabaco subrayan, pues su objetivo explícito es el de deslegitimar tal comportamiento y establecer una nueva norma social, la de no fumar. Esta intención viene subrayada con la publicación de los resultado de estudios estadísticos que indican que los fumadores son minoría y que la mayoría de los que fuman desean abandonar su hábito. Maneras eficaces de recalcar la condición de desviado de la norma del fumador son: asociarlo con la rebeldía, con la parte marginal de la sociedad (drogadictos, pobres, enfermos mentales, sin techo), y disociarlo de la civilización y las buenas costumbres. Que fumar ha pasado, en gran medida, a estar mal considerado queda evidenciado en hechos como que se recomiende a los que buscan empleo que no acepten fumar o el que se llegue al extremo de falsear la historia para hacer desaparecer el tabaco.

EMPIRIA. Revista de Metodología de Ciencias Sociales. N. ${ }^{\circ}$ 21, enero-junio, 2011, pp. 121-142. ISSN: $1139-5737$ 
Sin embargo, la creciente infamia del tabaco se encuentra con numerosas resistencias, pues la ideología procedente de los poderes gubernamentales no ha sido completamente absorbida sino que, incluso, ha generado reacciones en su contra, además de persistir numerosos vehículos de promoción de las connotaciones más placenteras del tabaco. Así, frente a su patologización, hay quienes destacan las virtudes y efectos benéficos del tabaco, así como su asociación con virilidad, sexualidad, alegría y juventud. Frente a la segregación del fumador y su expulsión de muchos lugares públicos, surgen nuevas maneras de promocionar el tabaco, así como formas de sociabilidad y compañerismo. Frente a su estigmatización puede hablarse de un culto al tabaco y a sus características sublimes y seductoras. Frente a la criminalización del fumador, pervive la convivencia pacífica entre fumadores y no fumadores. Por último, frente a la construcción del tabaquismo como conducta desviada de la norma social, el tabaco sigue gozando de gran importancia en la vida social, pues aún sirve para establecer y potenciar lazos sociales; además, sigue siendo un marcador de posiciones sociales.

\section{BIBLIOGRAFÍA}

Becker, H. S. (1966): Outsiders. Studies in Sociology of Deviance, Nueva York, The Free Press.

Canguilhem, G. (1970): Lo normal y lo patológico, Buenos Aires, Siglo veintiuno argentina editores.

CARr, A. (2003): Es fácil dejar de fumar, si sabes cómo, Madrid, Espasa.

CIS (2006): Tabaquismo y nueva normativa antitabaco.

Douglas, M. (1991): Pureza y peligro. Un análisis de los conceptos de contaminación y tabú, Madrid, Siglo XXI.

DuRKHEIM, E., Las formas elementales de la vida religiosa. Akal, Madrid, 1982.

Foucault, M (1992): Genealogía del racismo, Madrid, La Piqueta.

FouCAUlt, M. (1999): El nacimiento de la clínica. Una arqueología de la mirada médica, Madrid, Siglo XXI.

FoucAult, M. (2000): Vigilar y castigar, Madrid, Siglo XXI.

Freud, S. (1988): Tótem y Tabú. Alianza Editorial, Madrid, 1988.

GATEly, I. (2003): La diva nicotina. Historia del tabaco, Barcelona, Ediciones b.

GIRARD, R. (1986): El chivo expiatorio, Barcelona, Anagrama.

GIRARD, R. (1995): La violencia y lo sagrado, Barcelona, Anagrama.

GoldsteIn, A. (1995): Adicción, Barcelona, Ediciones en neurociencias.

GRAY, J. (2004): Al Qaeda y lo que significa ser modernos. Barcelona, Paidós.

Hatton, J. (2000): en R. Harris y J. Hatton, En defensa del tabaco. El gran debate. Madrid, Taller de Mario Muchnik.

KLEIN, R. (1994): Los cigarrillos son sublimes, Madrid, Tabapress.

LAMO DE Espinosa, E. (1993): Delitos sin víctima. Orden social y ambivalencia moral, Madrid, Alianza.

LIZCANO, E. (1999): «La metáfora como analizador social», en Empiria. Revista de metodología de ciencias sociales, $\mathrm{n}^{\mathrm{o}} 2$, Universidad Nacional de Educación a Distancia, pp. 29-60. 
MADRID, S. (2007): Los signos errantes. Estrategias de la publicidad gráfica española 1950-2000. Universidad de Murcia, Servicio de Publicacione, Cendeac.

MARCos, J.F. (1999): «Estrategias terapéuticas en el abordaje de la dependencia por nicotina», en J.J. Meada, I. Markez, y L. Pantoja (eds.): Nicotina y tabaquismo. Nuevas perspectivas. Avances en farmacología de drogodependencias. Bilbao, Universidad de Deusto.

RoDRíGUEZ DíAz, S. (2005): «La cruzada antitabaco como ejemplo de ingeniería social: una mirada crítica», en Mabel Gracia y Amado Millán (coords.) «Alimentación, salud y cultura: enfoques antropológicos», Trabajo social y salud, $\mathrm{n}^{\circ}$ 51. Asociación Española de Trabajo Social y Salud, julio 2005, pp. 401-416.

RodríGUEz DíAz, S. (2006): «Cruzadas modernas: el caso del tabaco», en Empiria. Revista de Metodología de Ciencias Sociales, $\mathrm{n}^{\circ} 12$, julio-diciembre 2006. Universidad Nacional de Educación a Distancia, pp. 125-140.

RoDríguez DíAz, S. (2007): «Todos contra el humo. Apuntes en torno a la guerra contra el tabaco», en Intersticios. Revista Sociológica de Pensamiento Crítico (www.intersticios.es): vol. $1, \mathrm{n}^{\circ} 1$, febrero 2007, pp. pp. 81-97.

RoDRÍGUEZ DíAz, S. y M. A. V. Ferreira (2008): «Diversidad funcional: sobre lo normal y lo patológico en torno a la condición social de la dis-capacidad, en Cuadernos de Relaciones Laborales, 28 (1): pp. 64-85.

RodríGuez DíAz, S. y M. A. V. Ferreira (2010): «Desde la dis-capacidad hacia la diversidad funcional. Un ejercicio de dis-normalización», en colaboración con Miguel A V. Ferreira, en Revista Internacional de Sociología, ${ }^{\circ}$ 68, pp. 289-309.

SonTAG, S. (2005) La enfermedad y sus metáforas. El sida y sus metáforas, Madrid, Suma de Letras.

SzASZ, T. (2001): Nuestro derecho a las drogas. Barcelona, Anagrama.

SÁNChez Noriega, J.L. (2002): Crítica de la seducción mediática. Comunicación y cultura de masas en la opulencia informativa. Tecnos, Madrid.

TRÍAs, E. (2006): Lo bello y lo siniestro, Barcelona, Random House Mondadori.

\section{RESUMEN}

En este artículo se propone un análisis de algunas de las estrategias que se han utilizado para convertir al tan extendido y popular hábito de fumar en una conducta desviada en el contexto de lo que se ha venido en llamar «cruzada antitabaco». Esto abarca tanto la creciente regulación y normalización del mundo del tabaco como la elaboración de un nuevo sistema ideológico, transmitido a través de campañas diseñadas para marcar negativamente a esta sustancia y a los que la consumen. Agruparemos tales estrategias en cinco dimensiones, que nos remiten a distintos ámbitos o niveles de análisis. Así, hablaremos de una patologización en términos médicos, de una segregación espacial, de una estigmatización que obedece a una lógica religiosa, de una criminalización que nos remite al campo de lo bélico, así como de una desviación de la norma que nos remite al terreno de lo social. 


\title{
PALABRAS CLAVE
}

Tabaco, cambio social, conducta desviada.

\begin{abstract}
This article proposes an analysis of some of the strategies that have been used to convert the popular and widespread habit of smoking in deviant behavior. This includes the increasing regulation and normalization of tobacco and the elaboration of a new ideological system, transmitted through campaigns designed to value negatively this product and those who consume it. We will distinguish five dimensions that refer to different areas or levels of analysis. Thus, we will talk of a pathologization in medical terms, of a spatial segregation, of stigmatization that leads to a religious logic, of criminalization which refers to the realm of war, as well as a deviation from the norm which refers to social domain.
\end{abstract}

\section{KEY WORDS}

Tobacco, social change, deviant behavior. 